\title{
The Evolution of Iranian French Learners' Spoken Interlanguage from a Cognitive Point of View
}

\author{
Marzieh Mehrabi ${ }^{1}$, Rouhollah Rahmatian ${ }^{1}$, Parivash $\operatorname{Safa}^{1} \&$ Novid Armiun ${ }^{1}$ \\ ${ }^{1}$ French Department, Tarbiat Modares University, Tehran, Iran \\ Correspondence: Rouhollah Rahmatian, French Department, Tarbiat Modares University, Tehran, Iran. Tel: \\ 98-21-8288-4648. E-mail: rahmatir@modares.ac.ir
}

\author{
Received: March 13, 2014 Accepted: April 18, 2014 Online Published: May 28, 2014 \\ doi:10.5539/ies.v7n6p117 URL: http://dx.doi.org/10.5539/ies.v7n6p117
}

\begin{abstract}
This paper analyzes the spoken corpus of thirty Iranian learners of French at four levels (A1, A2, B1 and B2). The data were collected in a pseudo-longitudinal manner in semi-directed interviews with half closed and open questions to analyze the learners' syntactic errors (omission, addition, substitution and displacement). The most frequent errors from A1 to B2 levels were determined and categorized, which allowed further analysis. The results show although some persistent errors are problematic at all levels, their form changes from one level to another. At A1 and A2 levels, the definite articles were missed before nouns, at B1 and B2, they were set aside in the second word of noun groups. In addition, at A1 and A2 levels errors are more of an interlingual nature while at B1 and B2 levels they are mostly intralingual. At elementary levels, learners deal with proactive transfers whereas in more advanced levels retroactive transfers and overextensions come into play.
\end{abstract}

Keywords: oral production, interlanguage, syntactic errors, Iranian learners of French

\section{Introduction}

Much of classroom exchange is through oral expression. According to Lafontaine (2002-2003), it has been shown that the spoken language contributes to the cognitive development of learners. In cognitive didactics, classroom exchanges contribute effectively not only to the construction of knowledge but also and in particular to shaping up interpersonal relations of the learners. The spoken language, apart from being a means of communication, is what allows communities to emerge.

In the past few years, speaking has received priority in the Iranian language classroom for a number of reasons: learning to speak, immigrating abroad, finding better job opportunities, getting a promotion at work, improving their speaking ability, etc. This led us to undertake the present research on cognitive didactics of oral expression. We part from the issue of how knowledge is organized when we speak. In this regard, we will focus on the way in which the oral interlanguage of Iranian learners develops from a syntactical point of view. In this paper, we will attempt to clarify how the interlanguage of Iranian learners evolves and which cognitive operations are most frequently used when they speak.

This research was carried out within the framework of cognitive didactics of languages (Billières \& SpangheroGaillard, 2005). It aims to shed light on vulnerable zones of oral expression among Iranian learners of French as a foreign language. We try, through some field study, to show how Iranian learners conceptualize complex acts (knowledge in a foreign language) and how they organize this knowledge, taking into account their cognitive development and their resort to interlanguage.

\section{Interlanguage}

Interlanguage is not limited to all the approaches that describe the process of acquisition of a foreign language. Two fundamental studies matured the concept of interlanguage, although the idea had already existed for a while. One was published by Corder in 1967 in International Review of Applied Linguistics, The significance of learners' errors, and the other by Selinker, Language transfer, published in 1969 in General Linguistics (Rosen \& Porquier, 2003). These researchers pioneered the research in this field and have since been considered as founding fathers of the field precursors of which are error analysis and the study of morphemes.

The concept was further developed by Selinker in an article titled Interlanguage which was published in International Review of Applied Linguistics in 1972. Experts in applied linguistics adopted a variety of terms to 
refer to this notion. Corder (1967) talked about "transitional competence" and later in 1971 of "transitional idiosyncratic dialects". Nemser (1971) proposed the concept of "approximate systems". However, it was the term "interlanguage" proposed by Selinker that was widely accepted among linguists.

It is to mention that the term interlanguage was not invented by Selinker. It was first used by the creolist, John Reinecke in his thesis in 1969 to describe the situation at the time of sugar plantation in Hawaii. He used the term to refer to nonstandard variation of the first or second language which was used as a means of communication among different groups, and which gradually approached the norms of the standard language of economically and politically dominant groups (Dewaele, 2003).

In language teaching and learning, Vogel (1995) defines interlanguage as the language that a foreign language learner develops as he confronts elements of the target language without completely overlapping it. According to Bange (1992), the interlanguage of a non-native speaker is a set of linguistic and pragmatic rules which are not necessarily coherent or complete but which the non-native speaker deems sufficiently compatible with the functions of the target language and which allows him to communicate.

Interlanguage is therefore a set of implicit know-hows which enable the non-native to speak a foreign language. It represents a transitory system between the languages already acquired by the learner and the target language and so may derive from those linguistic systems. Its existence implies an innovative readjustment between these systems by the learner: it is an open system of which the user himself is an integral part, a transitory system that cannot be considered closed which is only regulated from the inside. The reason behind the difficulty to define interlanguage is its duality: its being systematic and its being variable. It is systematic when it causes linguistic behaviors that are not arbitrary. However, it carries traits exclusive to each learner.

\subsection{What Influences the Evolution of the Interlanguage?}

The evolution of the interlanguage generally depends on individual as well as environmental factors:

- Learner-related factors: the background knowledge of the learner, his cognition, his learning experiences, his motivation, etc. are to be considered as individual factors.

- Didactical and pedagogical factors: objectives, sifting the content, teaching conditions, length of the class and teacher-related variables, similarities between previously-learned languages and the target language, etc. are among environmental factors.

- Task-related factors: a learner's interlanguage varies depending on the type of the task he does. A translation task, for instance, brings about more interference than a report-writing task or one may notice more pronunciation errors when reading a text aloud than when speaking. Tarone (1979) calls this phenomenon "chameleon effect" of the interlanguage.

\subsection{Stages in Interlanguage Development}

As we just mentioned, the stages in the development of the interlanguage depends on individual and social variables related to the learning situation as well as on methodological variables. According to Vogel (1995), all theoretical approaches to language learning agree on one thing: whether it is a baby learning the mother tongue, or some individual learning a foreign language, and whether it takes place in a natural or in an institutional environment, the process cannot be triggered without an input. This input may come from an interlocutor, a teacher, the media, texts, educational material, etc. The learner processes the input by elaborating hypotheses. This process is summarized in the following diagram. 


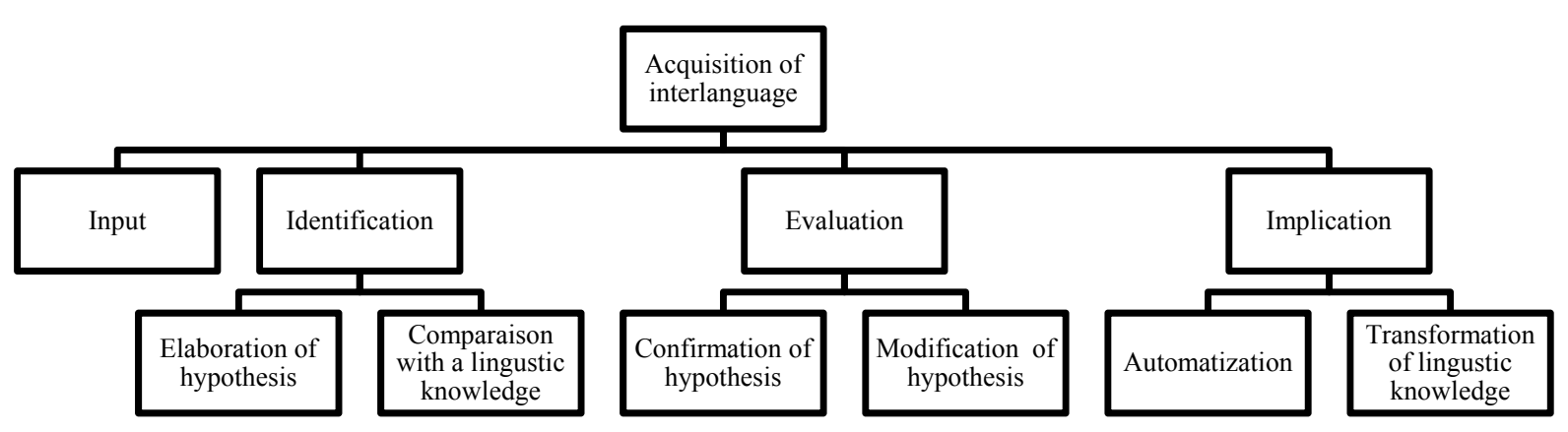

Diagram 1. Stages in the development of the interlanguage, receptive type

According to this model, known generally as receptive (Vogel, 1995), the learner with a given input first identifies in it the linguistic forms on which he bases his hypotheses and compares the input with the hypothetical rules. The learner then verifies whether the input corresponds with the hypotheses. If the answer is affirmative, the hypothetical rule is labeled as grammatically correct and stored in long-term memory. If the answer is negative, the learner will be led to restructuring this part of his linguistic knowledge. This, however, is not possible unless other input is sufficiently provided in order to compare, evaluate, and reformulate the initial hypothesis. Therefore, in case where a hypothesis is not confirmed, the learner has no choice but to maintain a cognitive control over the input related to that particular hypothesis.

Another model that is often known as productive (Vogel, 1995) suggests that the learner first activates the part of his interlinguistic knowledge with a higher chance of creating a hypothesis in the target language. He tries to verify the hypothesis either by formulating it linguistically in the target language or by offering metalinguistical explanations and evaluating the interlocutor's feedback. If the feedback is positive, the hypothesis will be confirmed, stored in the long-term memory, and retrieved if the need be. If negative feedback is received, the issue remains under cognitive control and sooner or later, a new hypothesis will be verified.

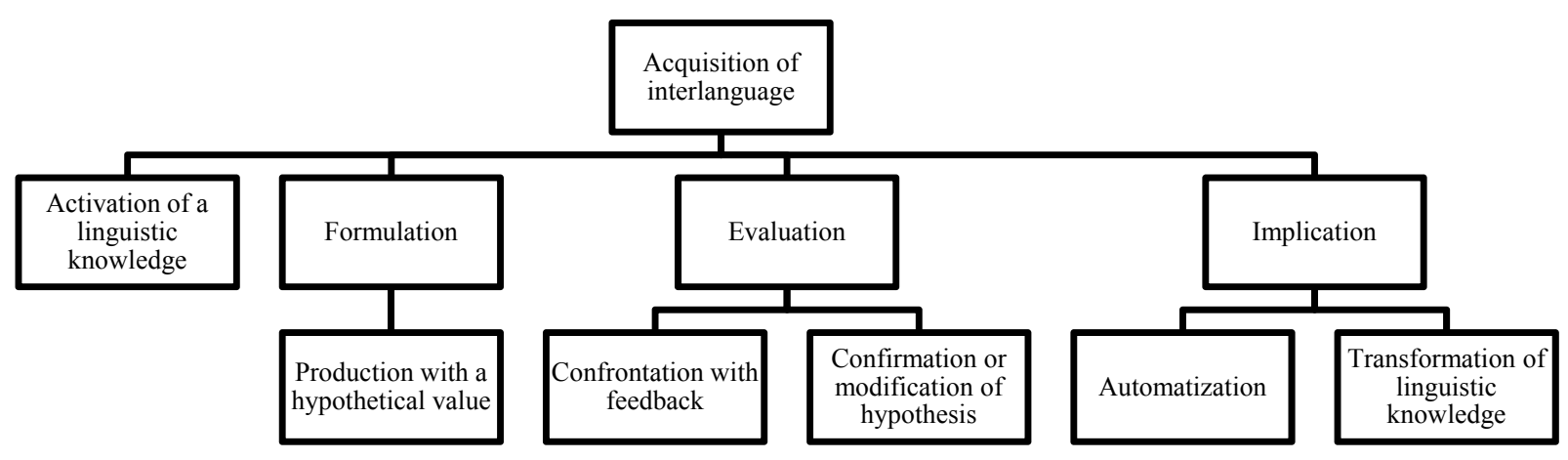

Diagram 2. Stages in the development of the interlanguage, productive type

In the process of learning a foreign language, a typically interlinguistic phenomenon, specially analyzed by Selinker (1972), may occur: fossilization. It is observed when the interlinguistic hypothesis ends up being stored in the long-term memory and may be retrieved at any moment.

\section{Applying Anderson's Theory to the Analysis of Spoken Interlanguage}

Spoken language is the result of a marriage between declarative knowledge on the one hand and procedural knowledge on the other. There are two major tendencies in theoretical debates:

- Process-based theories which consider the acquisition of a skill as a process. Anderson's is the best 


\section{known;}

- Memory-based theories which aim to explain how proficiency is achieved. Gordon Logan's instance theory is to mention here. According to this theory, a trace is automatically made in memory for each instance of processing. Consistent practice creates a vast collection of instances. The more there are instances in the memory, the faster one may find the trace should the need arise (Hilton, 2005).

The point these theories share is that the mastery of a language is the result of automatic cognitive processes. The key is to memorize and to repeat. We chose to base our research on Anderson's model whose latest version is called ACT*, the abbreviation of Adaptive Control of Thought. The asterisk signifies it is the modified version of the original model. This model was developed to take into account a variety of cognitive activities such as memory, language, learning, reasoning, decision making, etc. and includes three stages:

\section{Interpretative stage}

Cognitive, declarative, or interpretative stage implies that the skill that is to be acquired is encoded, either through instructions or through examples (Anderson, 1993, 1995) in order to allow the learner to exhibit the desired behavior, even if this has to be done gradually at first. During this first stage, the language plays a significant part. This is manifested by the learner repeating the information necessary for exhibiting the behavior. The information provided for the learner is still presented in declarative form and must be interpreted in order to be executed. This is the stage where the required rules for understanding a task are encoded.

At this stage, once a goal is achieved (an utterance is produced), the attention is drawn toward the next goal. Anderson (1983) believes that cognitive processing is serial since only one goal could be followed at a time. A lot of cognitive resources are required as the process necessitates keeping the declarative representation in the working memory.

Verbalizations, repetitions, and hesitations when speaking a foreign language characterize this stage. For the sake of example, during an interaction, the learner has to understand, and then elaborate an utterance by verbalizing the question posed and by thinking about its meaning.

\section{Associative stage}

This is the stage where knowledge is compiled. In computer language, it is the transformation of a source application (made by a programmer) to an executable application ( $0 \mathrm{~s}$ and $1 \mathrm{~s})$ by a compiler. The transformation of an initial declarative representation to a procedure is achieved thanks to a process of compilation. This is the gradual phase of conversion from declarative knowledge to procedural knowledge. The process of compilation may be divided into two sub-processes:

- Proceduralization process which gradually replaces the interpretative application (controlled, slow, little reliable, and cognitively costly) of productions by an automatic direct application that no longer necessitatesthe declarative knowledge used at the beginning of learning.

- It is the passage from controlled to automatic processing. Proceduralization reduces the cognitive load on the working memory since it is no longer necessary that the information coming from the long-term memory be kept there, which makes it possible to accomplish multiple tasks at once.

- Composition process through which several related utterances are sorted, regrouped, and compensated to produce a new unique utterance. This could be considered as a process of creating macroproductions which run the operations of a pair of productions are organized in sequence (Anderson, 1983). It allows the system to function increasingly economical by reducing the number of productions the system has to make to accomplish a given task.

The errors which characterize the previous stage are spotted and progressively eliminated. The learner's skill undergoes a gradual transformation, they become slightly more fluent, make fewer mistakes, and find verbalization less necessary. Self-corrections and soliciting corrections mark oral expression in a foreign language. When a learner speaks in the language they are learning, they begin with the transfer of meaning and break up this meaning into components and then turn to the sub-problems of generating each component. Each sub-problem is broken up to the point where the learner obtains the units of meaning corresponding to words or sentences.

Utterances that are produced in this way reveal several features which allow to bring the proceduralization process closer to the autonomous process. These utterances lead to increasingly faster and more solid behavior. 


\section{Autonomous stage}

The autonomous stage is a stage of adjustment and refinement of productions. During this stage, the skill constantly becomes more automatic and faster and requires fewer and fewer interventions of the cognition. In some cases, the learner even loses the capacity to verbally describe the skill. Thanks to practicing and repeating the procedures, the procedural knowledge is applied more adequately and rapidly. This is in fact the procedural phase which includes three mechanisms:

- Generalization which widens the scope of productions

- Discrimination which narrows the scope of productions

- Consolidation which reinforces the best productions and discourages the less acceptable ones. Internal and external feedbacks play a crucial role here.

The following diagram gives an overview of the above-mentioned stages.

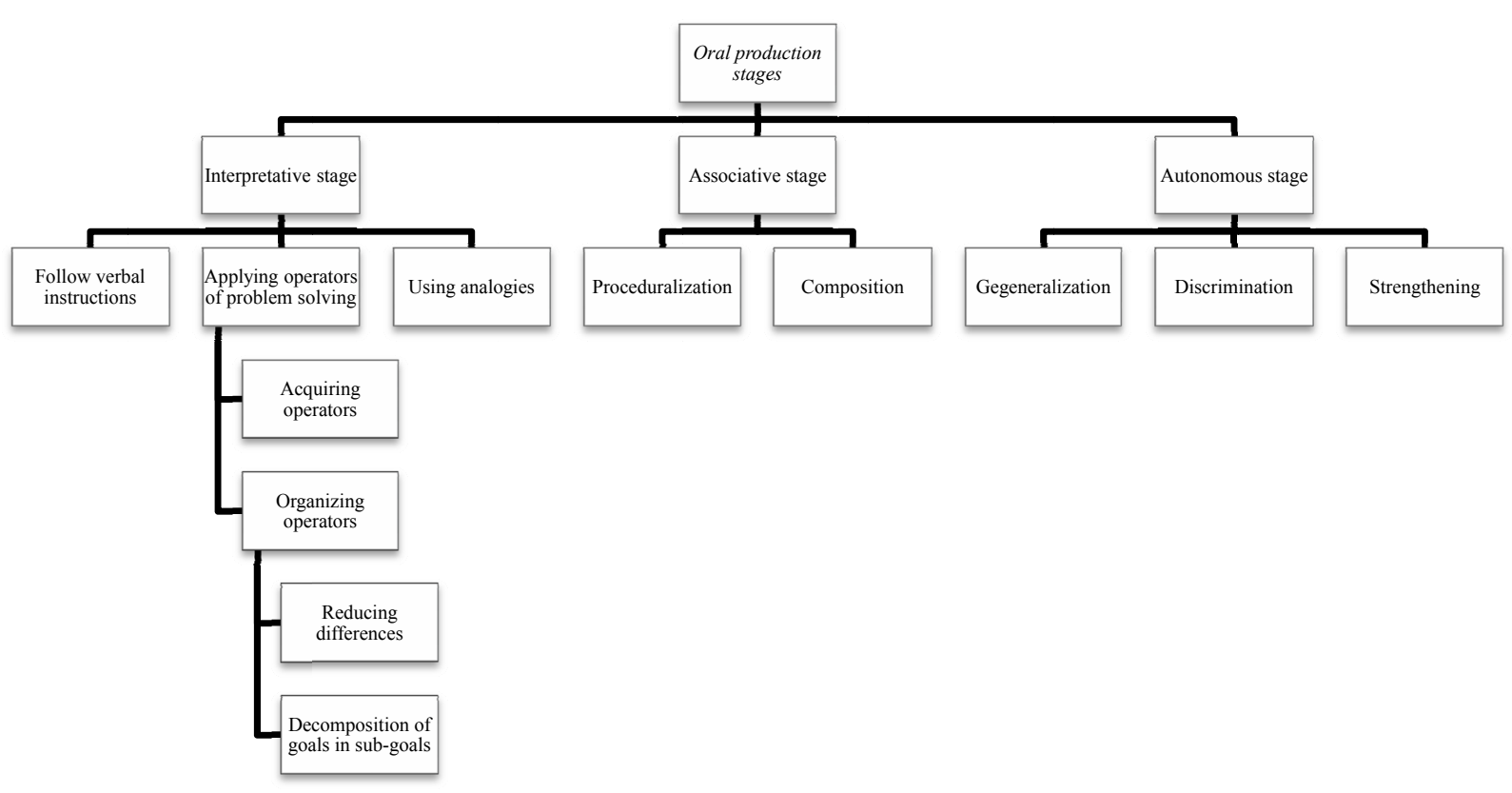

Diagram 3. Stages in oral production according to Anderson

This model considers an autonomous stage during which the cognitive load is reduced. Learners try to reduce the cognitive load, which explains why they try to keep in mind or memorize some linguistic structures. They prefer to reach a certain degree of spontaneity in producing ready-made phrases since they find it hardly possible to spend so much energy every time they need to produce an utterance. The ultimate goal of teaching/learning speaking is to reduce the cognitive load and to push learners toward spontaneity.

\subsection{Production Rules in ACT Theory}

The production rule is an $I F \ldots T H E N$ rule, that is a rule which specifies a condition (IF) and an action (THEN). It is also called a "condition-action" rule.

If the active information in the working memory matches the conditions of a production, then the production is spontaneously triggered. If the active information in the working memory matches several productions, then the conflict resolving rules intervene. For example, the specificity principle favors the initiation of procedures which consist of the largest number of conditions related to the information in the working memory, etc. It is to remind that it is the control of the cognitive system that entails this principle.

Example: if your goal is to produce the plural of "man" in English

And if you know that the plural of "man" is "men" 
Then say: men

Thanks to this rule, we may formulate the processes of analogy, generalization, and discrimination as presented in the following section.

\subsubsection{Generalization}

According to Anderson (1995), generalization algorithm looks for similarities in a couple of production rules and creates, based on them, a new production rule which contains what was common among the former rules. We may proceed with an example of the generalization in English:

R1 If you want to turn the verb "walk" to the past tense

then use the unmarked form "walk"

and add the suffix-ed

R2 If you want to turn the verb "jump" to the past tense

then use the unmarked form "jump"

and add the suffix-ed

Based on these two specific rules, one may induce (with the risk of overgeneralization)

R3 If you want to turn a verb to the past tense

then use the unmarked form of the verb

and add the suffix-ed

In such a case, new constraints should be applied to avoid the risk of overgeneralization. According to Anderson, learners constantly look to compare the procedural rules that they have just made to other procedural rules which already exist in order to see if a potential generalization is possible. That is the condition for productivity and therefore for the progress of learning. However, the general rule is not very solid at first as it is not based on a vast database. It will be put at test, which may lead to discrimination.

This period of overgeneralization is when learners start to reason in L2. They demonstrate the ability to infer the regularities of the language.

\subsubsection{Discrimination}

Thanks to the process of discrimination, the application of a procedural rule is restricted to only appropriate circumstances. Recognizing the exceptions of a general rule or adapting one's manner of speaking to a certain situation are examples of discrimination.

Generalization and discrimination are inductive components of the learning system because they try to extract examples of the characteristic features, allowing the learner to determine when a procedural rule is applicable.

Every time a rule is successfully applied, it is consolidated. External positive feedback plays a decisive part in consolidation. In contrast, if learners judge a rule as inadequate by a negative feedback, the rule is weakened and they try to construct new hypotheses. With successive executions, anticipation of results become more precise and mature, the process becomes less demanding and the cognitive resources are freed up. This is what Anderson calls knowledge proceduralization.

Sharing Bange's viewpoint (Bange et al., 2005), we believe that learning a foreign language is not like being gradually shaped in a prefabricated mold (L2 system), which regards learning as a passive process as in behaviorist concepts, or like a system dormant in the faculty of language, but like a progressive recreation, a construction based on general cognitive mechanisms.

\section{Field Study}

\subsection{Context}

The data were collected in the central branch of a big language institute, Ghotbe Ravandi, Tehran, Iran. It is to mention that the French language is taught as a foreign language in Iran. The official language is Persian and English is learned at schools as the first foreign language. French may be learned as the second foreign language at some universities or language schools where intensive or extensive courses are offered. The major course books currently in use are le Nouveau Taxi, Alter Ego, Écho, Reflets, etc.

\subsection{Corpus}

Thirty learners made up our corpus. Nine of them were at A1 level, six at A2, nine at B1, and six at B2 level. 
They were all 20 to 40-year-old adults, both males and females, whose mother tongue was Persian and, in some cases, Azeri, spoken by Turks in Iran. They could all speak English and their level ranged from beginner to advanced. They had all learned French in language schools or universities in Iran. Their contact with the French language was limited to institutional contexts, in classrooms with classmates and teachers. They did not use French to communicate with native speakers of French.

The approximate number of hours required to complete a level and pass to the next is 200. Each intensive course is held in 72 hours while extensive courses offer 36-40 hours of class. Our investigation was carried out throughout a semester.

Learners already had a notion of parts of speech thanks to either the languages they had already learned or the grammatical approach to teaching in their French classes.

\subsection{Methodology}

In order to conduct the field study, we adopted a quantitative and qualitative approach to interviewing. The interviews were individual and semi-guided with closed and open questions.

We also recorded class conversations during a semester which gave us an overview of the evolution of interlanguage through different levels (A1-B2) in a pseudo-longitudinal way.

Our study consisted of a speaking test where the interviewer asked questions to which the learners were supposed to answer. Depending on the learners' responses, the interviewer asked other questions in order to involve them in a spontaneous conversation. The learners did not have the time to prepare their utterances a priori and the whole process was recorded. We had a total of three and half hours of recording: 49 minutes for A1 level, 37 minutes for A2 level, 85 minutes for B1 level, and 39 minutes for B2 level.

It is to mention that the duration of the recordings was not decided in advance. What counted most was to give the learners the chance to express themselves without having to worry about time.

\subsection{Data Analysis}

To analyze the data, we adopted the content analysis technique which may be applied to all responses to how-and-why questions (Zihisire, 2011). Our approach to error analysis was to identify, classify, and interpret the errors.

The works of cognitive theoreticians who are interested in general principles of error production contributes greatly to teaching languages in spite of having a basically different scope. For cognitive psychology, error is in fact a gateway to mental processes to which there is no direct access (Larruy, 2003). The analysis of errors and their causes in the course of learning a foreign language has shown that not only may errors explain the phenomena of evolution and planification of a language, but they could also be interpreted effectively as being systematic and stem from rules.

It is needless to say that in order to identify the error, one must have a norm to compare it to. According to Ogien (2009), to identify an error, one must know the standard and adequate way of doing a given act.

As for classification, we chose sample-based classification: errors were first collected and interpreted. We then established an appropriate taxonomy.

Regarding the interpretation of errors, we tried to offer the most plausible interpretation since the learners were absent at this stage and we had to guess what they meant to convey.

\section{Results and Discussion}

We noted errors of omission, addition, substitution, and in certain cases, displacement. Once the errors were categorized, they were coded to be localized. The following diagram summarizes these categories.

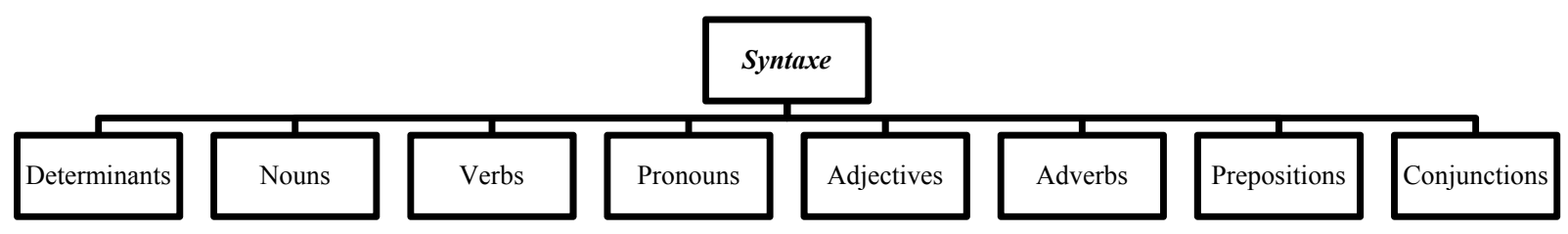

Diagram 4. Syntactical components of the error analysis 
The analysis of the learners' non errors showed that the preexisting notions in languages already learned are more deeply carved into their memory (the non errors in case of the omission of a possessive or demonstrative adjective are the proof).

The analysis of the errors in our corpus helped us to better understand the evolution of the interlanguage of Iranian learners of French as a foreign language. Non persistent errors are mainly interlingual errors whereas persistent errors are mostly intralingual. Here we may refer to substituting the present tense, omitting the definite articles, substituting nouns, conjugating verbs at present, and substituting prepositions. To be more precise, errors at A1 level mainly included bad verb conjugation and at A2, B1, and B2 levels were wrong word choices and inappropriate prepositions.

For instance, learners tend to invert the order of proper nouns. Knowing that Persian and French have little in common, they resort to their knowledge of English, leading to the emergence of such errors. This kind of error has to occur under the influence of the English language because in Persian proper noun order is identical to that in French. This error, being interlingual, is far from being persistent.

It is worthy of mention that among linguistic structures, those which do not exist beforehand in the learners' cognitive knowledge (notions inexistent in the mother tongue and whose command are not yet good in a foreign language they have already learned) prove to be more problematic and a source of error, as it is the case of definite articles that do not exist in Persian. Although this grammatical category exists in English - the first foreign language of the learners -the mastery of its use remains incomplete.

At times, the input on the workings of the target language is poor or deficient and the rules are not thoroughly explained. As a result, it will be more likely that overgeneralization and indiscrimination of rules occur and consequently learners are pushed toward producing an erroneous utterance. When the different contexts in which a certain rule is applied are not clearly described, learners tend to overgeneralize the rule. Recent approaches to language teaching, particularly the communicative and task-based approaches which emphasize the importance of the meaning and conveying the message in communication to the point that they leave behind the grammatical rules used in speech acts. That is prioritizing the meaning to the detriment of linguistic forms. Thus, erroneous utterances are reinforced by several cognitive operations. The following examples show how overgeneralization leads to grammatically incorrect forms.

la rôle de technologie $=$ the role of technology

c'est par exemple un façon = that's for example a way

Procedural rules could be reformulated as:

Rule 1: If all the words ending to e are feminine,

Then the word "rôle" is feminine.

Rule 2: If all the words ending to nasal sounds are masculine,

Then the word "façon" is masculine.

Moreover, there were learners in our corpus who made an inference in order to make up the word they did not know in French. The examples below show how the learners, under the influence of English, used the words "nouveaux" and "neufs" to say "news" in French.

If in English "news" is "new" plus s,

Then its French equivalent must be "nouveau" or "neuf" plus s.

je regardes les nouveaux = I watch the "nouveau"

je regarde les neufs = I watch the "neuf"

Furthermore, in some cases, they made sentences based on analogy. The learners presupposed that certain English structures were the same in French and therefore made interlingual errors. This is caused by some sort of mental translation from previously-learned languages into the target language.

Je suis trente ans = I am thirty years old (Note that in French the verb "avoir" (to have) must be used, so the word-by-word translation from French would be "I have thirty years").

Interestingly, sometimes even when the learners failed to retrieve a French word from memory, either because they simply did not know the word or because they just could not remember it, they would use an English or Persian word, being well aware of its inadequacy. This is how their just-get-the-message-through strategy wins. However, this was most commonly observed among learners at A1 level. 


\section{Je suis staff.}

When learners at B1 and B2 levels lacked a particular word, their strategy largely consisted of paraphrasing not only in order to maintain the conversation but also to learn the word they lacked. This is what De Pietro et al. (1989) call potential sequence of acquisition, a kind of interactive sequence which particularly favors the acquisition of a new element of the target language. In the following example, the learner adds a new term to his lexicon through heterostructuring (Py, 1990).

Learner: il y a eh quelque chose de matier de plastique = there's something of plastic Interviewer : une nappe tu veux dire $=$ a table cloth you mean

The form of some types of errors evolve from one level to another. For instance, while learners at A1 and A2 levels used Persian or English words if they did not know its French equivalent, learners at B1 and B2 levels tended to use inappropriate synonyms.

J'ai TOEFL et c'est mon marque c'est 120 (the French "marque" is a bad synonym for "note" which means "mark" in English)

Je ne crois jamais sur cet eh sujet- sur ce sujet (the French "crois" is a bad synonym for "pense" which means "think" in English)

Je ne dépense pas mon temps pour (The French "dépense" is a bad synonym for "passe" which means "spend" in English)

Omission of definite articles undergo some noteworthy evolution as well. At A1 and A2 levels, this error is seen before words or after using a preposition where contracted articles are needed whereas in B1 and B2 levels, the learners dropped the article before the second word in compound nouns.

le rythme de Ø vie

We also noticed that at B2 level, whenever the cognitive load of preparing a sentence is relatively heavy, persistent errors emerge.

$\varnothing$ natation c'est un sport que : vous faisez dans par exemple en été.(omission of the definite article and wrong verb conjugation)

In addition, there were cases of francization of English words in pronunciation. Learners try to make up lexical forms during the interaction under the influence of other languages they know (Hammaberg, 2006). The learners resorted to English to compensate for their lack of French vocabulary. This code switching, however phonologically adapted to French, is morphologically incompatible.

à cause de cette phenomenon (The French word is "phénomène")

Je désigner certains groupes d'équipement pour eh relative de petroleum eh industrie de petroleum. (The French word is "pétrole")

At B1 and B2 levels errors may derive from overextension. This happens when the learner tries to show off his linguistic abilities by using a particular word that is more prestigious than the other, or a certain structure which is more complicated than the other, resulting in an erroneous utterance. In the examples below, the learner uses the past tense instead of the present because the past tense has a more complex structure.

Je me suis servi de mon ordinateur (instead of saying "je me sers de mon ordinateur" = I use my computer)

J'ai compris turque (instead of saying "je comprends le turque" = I understand Turkish)

There were also cases of fossilization where learners repeated the mistakes when they used speech acts expressing what they had learned in the beginning of their learning process such as speech acts expressing one's job, languages, field of study, etc.

Je travaille à un bureau de conseiller (instead of saying "Je travaille à un bureau de conseil" = I workat an advising center)

The analysis of the errors and non-errors in our corpus show that of the three cognitive operations of generalization, discrimination, and consolidation, the learners would rather use generalization, which often leads to overgeneralization. Learners who inferred and generalized produced more utterances than those who did not. This is to say that they are more fluent in oral production.

It is to mention one more time that in our corpus, there were learners whose mother tongue was Azeri, spoken by Turks in Iran. The analysis of their errors did not reveal any differences from the errors of Persian-speaking learners. This might be justified by active and dormant languages at the time of production. Most learners' active 
language in the class was English and for some it was Persian.

In general, the interviewer corrected the learners by reformulating their answers correctly. However, in some cases, the learners' attention was so drawn to their own utterances or elaborating the next ones that they did not notice her corrections. This is an indication of the heavy cognitive load for preparing the utterances and the order of attention in the cognitive phase.

Although the grammatical heritage of learners could be a source of even unsurmountable difficulties, teachers simply cannot wipe the slate clean and start all over again. A fundamental principle in the learning process is to relate the newly-presented to already-learned material. An efficient teaching strategy takes into account the grammatical culture of the learners (Barbazan, 2007). Since our error categories are by no means exhaustive, we propose changing the context of oral production to make a more comprehensive list.

\section{Conclusion}

Learning a foreign language as procedural knowledge is a gradual process through which the learners' abilities are developed. Each level is marked by the presence of certain errors which generally disappear in the next level. Within each level, learners correct themselves as they speak. We may therefore say that learning is not a linear process. This means during the passage from a controlled process to an autonomous one, both processes combine.

Knowing each level and its typical errors, teachers are able to consciously decide what to correct, what risks to be fossilized, and what will be resolved once the learner completes the level.

Those learners who make more hypotheses on the workings of the language, that is, those who often use mental operations (analogy, inference, generalization, etc.) are more fluent. They take more risk as they speak even at the cost of accuracy.

Errors must be judged from a different point of view. Most often they are creative gaps compared to the norms of the target language, indicate the learner's exploratory behavior applying generative rules, and are part of the continuous process of differentiation which allows them to refine their knowledge of the language they learn. This is the reason why learners should never be penalized for their erroneous utterances. Thus, to understand a language learner is to pay attention to their psychological, linguistic, and psycholinguistic components and also to the context they are in and to the way their interlanguage evolves.

In practice, learner errors are a rich source to make use of. The authors recommend dealing with learner errors in depth, avoiding immediate and simple correction of them. It is preferable that teachers point to the errors afterward, especially to those more frequently made. This is how learners are guided toward self-correction.

Teachers of French in Iran may adopt a negotiating approach. By discussing the errors with each learner, not only do they become conscious of their mistakes, but they also become engaged in trying to remedy them.

\section{References}

Anderson, J. R. (1993). Rules of the mind. Hillsdale, NJ: Erlbaum.

Anderson, J. R. (1995). Learning and memory: An integrated approach. New York: John Wiley \& Sons.

Anderson, J. R. (1983). The Architecture of Cognition. Massachusetts: Harvard University Press.

Bange, P. (2005). L'apprentissage d'une langue étrangère: Cognition et interaction. Paris: L'Harmattan.

Barbazan, M. (2007). Les temps verbaux du passé: Quelle didactique pour le FLE? Repères linguistiques et cognitifs. Colloque International de Didactique Cognitive des Langues, Toulouse.

Billières, M., \& Spanghero-Gaillard, N. (2005). La didactique cognitive des langues: Regards croisés de disciplines. Comment comprendre le comment? Revue Parole.

De Pietro, J.-F., Matthey, M., \& Py, B. (1989). Acquisition et contrat didactique: Les séquences potentiellement acquisitionnelles dans la conversation exolingue. Actes du 3ème colloque régional de linguistique. Strasbourg, Université de Strasbourg.

Dewaele, J. M. (2003). Compte rendu-hommage: L'œuvre de L. Selinker. Linx [En ligne], 49|2003, mis en ligne le 18 mars 2011. Retrieved from http://linx.revues.org/564

Hammaberg, B. (2006). Activation de L1 ET L2 lors de la production orale en L3. Acquisition et interaction enlangue étrangère, $n$ 24. [En ligne], 24|2006, mis en ligne le 30 juin 2009. Retrieved from http://aile.revues.org/1641

Hilton, H. (2008). Connaissances, procédures et production orale en L2. Acquisition et interaction enlangue 
étrangère [En ligne], 27|2008. Retrieved from http://aile.revues.org/4113

Lafontaine, L. (2002-2003). Rapport intermédiaire, Projet de Recherche franco-québécois. Oral, savoirs, socialisation. Compétences langagières orales de la maternelle au collège, dans leur relation à la socialisation et aux apprentissages: prise de parole, conduites discursives, lexique, métacognition. Retrieved from http://www.lizannelafontaine.com/.../rapport_intermediaire

Laurruy, M. M. (2003). L'interprétation de l'erreur. Paris: CLE international.

Ogien, A. (2009). Le non-lieu de l'erreur. Sous la direction de Chauviré \& Ch, Ogien, A. Dynamique de l'erreur. Paris: Éditions de l'École des hautes études en sciences sociales.

Py, B. (1990). Les stratégies d'acquisition en situation d'interaction, Gaonac'h, D. (coord.), Acquisition et utilisation d'une langue étrangère. L'approche cognitive. Paris: Hachette.

Rosen, É., \& Porquier, R. (2003). Présentation. L'actualité des notions d'Interlangue et d'interaction exolingue. Linx [En ligne], 49|2003. Retrieved from http ://linx.revues.org/524

Tarone, E. (1979). Interlanguage as chameleon. Language Learning, 29(1), 181-191. http://dx.doi.org/10.1111/j.1467-1770.1979.tb01058.x

Vogel, K. (1995). L'interlangue la langue de l'apprenant. Traduit de l'allemand par Jean-Sébastien Roux et Patrick Bonin. Toulouse: Presses Universitaires du Mirail II.

Zihisire, M. M. (2011). La recherche en sciences sociales et humaines: Guide pratique, méthodologie et cas concrets. Paris: L'Harmattan.

\section{Copyrights}

Copyright for this article is retained by the author(s), with first publication rights granted to the journal.

This is an open-access article distributed under the terms and conditions of the Creative Commons Attribution license (http://creativecommons.org/licenses/by/3.0/). 